\title{
EDITORIAL
}

\section{WHO's ICD-11 for Primary Health Care}

\author{
Rebeca Robles-García, ${ }^{1}$ Geoffrey M. Reed ${ }^{2}$
}

\footnotetext{
1 Dirección de Investigaciones Epidemiológicas y Psicosociales, Instituto Nacional de Psiquiatría Ramón de la Fuente Muñiz.

2 Department of Mental Health and Substance Abuse, World Health Organization.
}

Correspondence:

Rebeca Robles García

Dirección de Investigaciones Epidemiológicas y Psicosociales, Instituto Nacional de Psiquiatría Ramón de la Fuente Muñiz.

Calz. México-Xochimilco 101

14370 Ciudad de México, México

Phone: +52 (55) 4160-5143

E-mail: reberobles@imp.edu.mx

https://doi.org/10.17711/ SM.0185-3325.2017.006
Given the high prevalence of chronic diseases such as diabetes or HIV/AIDS among individuals with mental disorders, there is a need to undertake special efforts to identify and address both mental health and other medical issues in this population on a timely basis.

In order to address mental health problems more effectively, health professionals need better tools and strategies for their detection and management. For this reason, one key project of the World Health Organization (WHO) Department of Mental Health and Substance Abuse is that the development of the classification of mental and behavioral disorders in the forthcoming ICD-11 (International Classification of Diseases, Eleventh Revision) to more effectively identify people in need of mental health services. In the words of the International Advisory Group for this project:

"People are only likely to have access to the most appropriate mental health services when the conditions that define eligibility and treatment selection are supported by a precise, valid, and clinically useful classification system." (International Advisory Group for the revision of the ICD-10 Mental and Behavioural Disorders, 2011, pp. 90).

Due to the significant treatment gap for mental disorders, as well as the shortage of mental health professionals around the world, it has been proposed that the identification and management of common mental disorders needs to be carried out in primary care settings. For this reason, in addition to a version of ICD-11 mental and behavioral disorders for use by mental health specialists, it was considered important to develop a version for use by primary health care providers. In accordance with the mission of WHO to reduce the global burden of disease, an important goal of this process has been to improve the clinical usefulness of this nosological system.

The proposed ICD-11 classification of mental disorders for primary care consists of 27 mental disorders considered to be most clinically relevant in these settings, either because they are common (such as depression) and/or because it is important that they are recognized by first-contact health care providers (e.g., schizophrenia or autism, which although not common in primary care, are important to identify so that they are properly addressed or referred for specialized treatment when possible and appropriate) (Goldberg, 2011). The ICD-11 classification of mental disorders for primary care practice has been developed not simply by summarizing the specialist classification but rather based on an evaluation of the needs and priorities of primary care practice (Gask, Klinkman, Fortes \& Dowrick, 2008).

Additionally, as has been done with the ICD-11 classification of mental disorders for specialists, the revised proposals have been evaluated in field studies. ICD-11 studies inprimary care settings have emphasized high-prevalence disorders associated with significant disease burden, and for which clinical descriptions have been modified substantially. This includes mood and anxiety disorders, as well as the occurrence of multiple somatic symptoms associated with significant distress and functional impairment (Lam et al., 2013; Goldberg et al., 2017; Goldberg et al., 2016).

The WHO Department of Mental Health and Substance Abuse has also developed and evidence-based management guidelines specifically designed for implementation in primary care settings as part of the WHO Mental Health Gap Programme (WHO, 2016). Using these management guidelines, first-contact health care provider who has identified any of the mental disorders included in the significant mental health issues, can determine 
the best way to begin managing the condition, or whether the best course of action is to refer the individual to a mental health specialist (when this is feasible within the particular environment).

Finally, in the case of new diagnoses proposed for the ICD-11 classification of mental disorders for primary care, treatment models, based on techniques that have proven effective, are being designed and evaluated. For example, in the case of the new proposed category called "Body Stress Syndrome" (BSS) a modular treatment for depression, anxiety and somatic symptoms was designed -considering the relationship of the somatic responses to stress with symptoms of depression and anxiety as confirmed in one of the field studies (Goldberg et al., 2016). This intervention was based on having confirmed cognitive behavioral techniques: behavioral activation, training in deep breathing and in Jacobson's muscle-pair relaxation, identification and modification of thoughts related to depression and anxiety, and exposure and significance of physical symptoms. This intervention proved effective in Mexican patients with BSS, and several primary care providers from different countries its relevance and feasibility for implementation in their workplaces (Robles, 2016).

In conclusion, it is evident that these tools can make an important contribution to the development of the capacity of primary care professionals to be more involved in the management of the mental health problems experienced by their patients. However, adoption of these practices will also depend on the raising awareness and providing training for primary care professionals in their particular contexts. Only through reducing stigma and fear through motivation and knowledge can the identification and treatment of primary care mental disorders in primary care settings become a daily reality.

\section{REFERENCES}

Gask, L., Klinkman, M., Fortes, S., \& Dowrick, C. (2008). Capturing complexity: the case for a new classification system for mental disorders in primary care. European Psychiatry, 23(7), 469-476.

Goldberg, D. (2011). A revised mental health classification for use in general medical settings: the ICD-11-PHC. International Psychiatry, 8(1), 1-3.

Goldberg, D. P., Reed, G. M., Robles, R., Minhas, F., Razzaque, B., Fortes, S., ... \& Saxena, S. (2017). Screening for anxiety, depression, and anxious depression in primary care: A field study for ICD-11 PHC. Journal of Affective Disorders, 213, 199-206.

Goldberg, D. P., Reed, G. M., Robles, R., Bobes, J., Iglesias, C., Fortes, S., ... \& Saxena, S. (2016). Multiple somatic symptoms in primary care: A field study for ICD-11 PHC, WHO's revised classification of mental disorders in primary care settings. Journal of Psychosomatic Research, 91, 48-54.

International Advisory Group for the Revision of ICD-10 Mental and Behavioural Disorders. (2011). A conceptual framework for the revision of the ICD-10 classification of mental and behavioural disorders. World Psychiatry, 10(2), 86-92.

Lam, T. P., Goldberg, D. P., Dowell, A. C., Fortes, S., Mbatia, J. K., Minhas, F. A., \& Klinkman, M. S. (2013). Proposed new diagnoses of anxious depression and bodily stress syndrome in ICD-11-PHC: an international focus group study. Family practice, 30(1), 76-87.

Robles R. (2016). Tratamiento psicosocial de pacientes con síntomas somáticos sin causa médica: el caso de México. En el taller: Diagnosing and treating medically unexplained symptoms: proposals from ICD-11 PHC. Trabajo presentado en el 21st WONCA World Conference of Family Doctors. Río de Janeiro, Brasil, 2 al 6 de Noviembre de 2016.

World Health Organization. (2016). mhGAP intervention guide for mental, neurological and substance use disorders in non-specialized health settings. Version 2.0. Ginebra: World Health Organization. 